\title{
Modeling imidazolium-based ionic liquids with ePC-SAFT
}

\author{
Xiaoyan Ji ${ }^{\mathrm{a}}$, Christoph Held ${ }^{\mathrm{b}}$, Gabriele Sadowski ${ }^{\mathrm{b}, *}$ \\ a Division of Energy Science, Luleå University of Technology, 97187 Luleå, Sweden \\ b Department for Biochemical and Chemical Engineering, TU Dortmund, Dortmund, Germany
}

\section{A R T I C L E I N F O}

\section{Article history:}

Received 15 February 2012

Received in revised form 10 May 2012

Accepted 14 May 2012

Available online 23 August 2012

\section{Keywords:}

Equation of state

PC-SAFT

Gas solubility

Ionic liquids

$\mathrm{CO}_{2}$

$\mathrm{CH}_{4}$

\begin{abstract}
A B S T R A C T
ePC-SAFT was used to investigate the density and gas solubilities in imidazolium-based ionic liquids (ILs) applying different modeling strategies. The ion-based strategy including a Debye-Hückel Helmholtzenergy term to represent the ionic interactions describes the experimental data best. For this strategy, the IL was considered to be completely dissociated into a cation and an anion. Each ion was modeled as non-spherical species exerting repulsive, dispersive, and Coulomb forces. A set of ePC-SAFT parameters for seven ions was obtained by fitting to reliable density data of pure ILs up to 1000 bar with a fitting error of $0.14 \%$ on average. The model can be used to quantitatively extrapolate the density of pure ILs at temperatures from 283 to $473 \mathrm{~K}$ and pressures up to 3000 bar. Moreover, this strategy allows predicting $\mathrm{CO}_{2}$ solubilities in ILs between 293 and $450 \mathrm{~K}$ and up to 950 bar. Applying the same set of IL parameters, the much lower solubility of $\mathrm{CH}_{4}$ compared to $\mathrm{CO}_{2}$ can also be predicted with ePC-SAFT.
\end{abstract}

(c) 2012 Elsevier B.V. All rights reserved.

\section{Introduction}

Ionic liquids (ILs) are salts that are liquid at room temperature and have almost no vapor pressure. Thus, ILs are considered to be environmentally benign solvents. Their properties mostly depend on their chemical constitution, which makes it possible to design a particular IL to meet a specific application. ILs have shown great potential to be used as liquid absorbents for $\mathrm{CO}_{2}$ separation because of the high $\mathrm{CO}_{2}$ solubility compared to other common components, such as $\mathrm{H}_{2}, \mathrm{~N}_{2}, \mathrm{CO}, \mathrm{O}_{2}$, and $\mathrm{CH}_{4}$, and lower energy requirements for regeneration [1,2].

The investigation of ILs for $\mathrm{CO}_{2}$ separation requires knowledge of the solubility of $\mathrm{CO}_{2}, \mathrm{CH}_{4}, \mathrm{~N}_{2}, \mathrm{H}_{2}, \mathrm{CO}, \mathrm{O}_{2}$, and their mixtures in ILs as well as understanding the dependence of thermodynamic properties (e.g. $\mathrm{CO}_{2}$ solubility) on microscopic structures (cation, anion, and the length of alkyl substituents). The solubility of pure gases and gas mixtures in ILs has been measured extensively [2-9]. Since the experimental determination is often difficult, time-consuming, and expensive, it is highly desirable to develop theoretical models for estimating the gas solubility in ILs over a wide range of conditions. At the same time, modeling gives insight into fundamental factors that control the solubility and selectivity of gases.

Different theoretical models have been proposed to represent the gas solubility in ILs [10]. Among these approaches, statistical associating fluid theory (SAFT)-based models were

\footnotetext{
* Corresponding author. Tel.: +49 231755 2635; fax: +49 2317552572.

E-mail address: g.sadowski@bci.tu-dortmund.de (G. Sadowski).
}

recommended due to their physical background. Several SAFTbased models have been developed. For example, the solubility of $\mathrm{CO}_{2}, \mathrm{CO}, \mathrm{O}_{2}$, and $\mathrm{CHF}_{3}$ in imidazolium-based ILs was represented with truncated Perturbed-Chain Polar SAFT (tPC-PSAFT) $[11,12]$. In these works, the ILs were modeled as polar chain molecules and $\mathrm{CO}_{2}$ was modeled as a quadrupolar molecule. Lewis acid-base type of association was assigned between IL and $\mathrm{CO}_{2}$, and temperature-dependent interaction parameters were used to adjust the cross-dispersion energy between IL and gas. Using soft-SAFT, the $\mathrm{CO}_{2}$ solubility in $\mathrm{BF}_{4} 4^{-}, \mathrm{PF}_{6}-$, and $\mathrm{Tf}_{2} \mathrm{~N}$-imidazoliumbased ILs as well as $\mathrm{H}_{2}$ and $\mathrm{Xe}$ in $\mathrm{Tf}_{2} \mathrm{~N}$-imidazolium-based ILs were studied $[13,14]$. These ILs were modeled as neutral chain molecules with association sites describing the specific interactions due to charges. $\mathrm{CO}_{2}$ was modeled as a quadrupolar molecule. Cross-interaction parameters were used to adjust the dispersion energy between IL and $\mathrm{CO}_{2}$; cross association between IL and $\mathrm{CO}_{2}$ molecules was not taken into account. Using heterosegmented SAFT, the density of $\mathrm{BF}_{4}-, \mathrm{PF}_{6}{ }^{-}$, and $\mathrm{Tf}_{2} \mathrm{~N}$-imidazolium-based ILs, the corresponding $\mathrm{CO}_{2}$ solubility, and the molar volumes of $\mathrm{CO}_{2}-\mathrm{IL}$ systems were represented [15-17]. The IL was considered to consist of a chain-like cation and a spherical anion with each one having association sites to account for the electrostatic/polar interactions. Cross association was assigned between $\mathrm{CO}_{2}$ and anion describing the Lewis acid-base interactions, and cross-interaction parameters were needed to adjust the dispersion energy between $\mathrm{CO}_{2}$ and IL.

To sum up, many SAFT-based models already exist in the literature, which all need binary fitting parameters. However, this procedure does not allow for model predictions. Therefore, the goal of this work is to develop a predictive model to represent the gas 
solubility in ILs. This is specially required for $\mathrm{CO}_{2}$ as the $\mathrm{CO}_{2}$ solubility in ILs can vary from very low to more than $80 \%$ in mole fraction. The Perturbed-Chain SAFT (PC-SAFT) model has been proposed [18] and widely used for systems containing non-polar as well as associating and polar substances including gases, solvents, biomolecules, and polymers [19-26]. The polar term has been included to consider the multi-polar interactions [27-29].

Recently, this model was extended to solutions with electrolytes (ePC-SAFT) [30-32]. In this work, the gas solubility in $\mathrm{BF}_{4}-, \mathrm{PF}_{6^{-}}$, and $\mathrm{Tf}_{2} \mathrm{~N}$-imidazolium-based ILs and the density of these pure ILs will be investigated with different strategies based on ePC-SAFT only. The strategy providing the best results will be presented in detail.

\section{Theory}

\section{1. ePC-SAFT}

In ePC-SAFT, the dimensionless residual Helmholtz energy is defined as:

$a^{\text {res }}=a^{\text {hc }}+a^{\text {disp }}+a^{\text {assoc }}+a^{\text {ion }}+a^{\text {polar }}$

where the superscripts refer to terms accounting for the residual, hard-chain, dispersive, associative, ionic, and polar interactions, respectively. The terms for $a^{\mathrm{hc}}, a^{\text {disp }}, a^{\text {assoc }}$, and $a^{\text {polar }}$ were described elsewhere [18,27-29]. The term $a^{\text {ion }}$ (Coulomb forces) was represented with the Debye-Hückel theory [33], i.e.

$a^{\text {ion }}=-\frac{\kappa}{12 \pi \cdot \varepsilon} \cdot \sum_{j} x_{j} q_{j}^{2} \chi_{j}$

where $x_{j}$ and $q_{j}$ are the mole fraction and the charge of ion $j$, respectively, $\varepsilon$ is the dielectric constant of the medium, and $\kappa$ is the inverse Debye screening length. The quantities $\kappa$ and $\chi_{j}$ are defined in the original ePC-SAFT publication [33].

ePC-SAFT models a pure substance $i$ with a maximum of five parameters: the segment number $m_{\text {seg,i, }}$, the segment diameter $\sigma_{i}$, the van der Waals-interaction (dispersion) energy parameter between two segments $u_{i} / k_{B}$ in which $k_{B}$ is the Boltzmann constant. For molecules with association interactions, $N$ association sites per molecule are characterized by the association-energy parameter $\varepsilon^{\mathrm{AiBi}} / k_{B}$ and the association-volume parameter $\kappa^{\mathrm{AiBi}}$. Generally, these parameters are determined by fitting to liquid-density and/or vapor-pressure data of a pure component. In case of ILs that are hardly volatile, only density data was used for the parameter fitting in this work.

Lorenz-Berthelot - combining rules are used for mixtures:

$\sigma_{i j}=\frac{1}{2}\left(\sigma_{i}+\sigma_{j}\right)$

$u_{i j}=\sqrt{u_{i} u_{j}}\left(1-k_{i j}\right)$

where $k_{i j}$ is a binary parameter between two components $i$ and $j$ and can be used to correct the cross-dispersion energy. This parameter (if required) is usually determined by fitting to binary data, e.g. to the gas solubility in ILs.

\subsection{Gas solubility}

In this work the phi-phi approach is applied to describe the equilibrium condition between the vapor and liquid phases. The fundamental relations are:

$y_{i} \varphi_{i}^{V}\left(T, v^{V}, y_{i}\right)=x_{i} \varphi_{i}^{L}\left(T, v^{L}, x_{i}\right)$ for all componentsi

where $y_{i}$ and $x_{i}$ are vapor and liquid mole fractions, respectively, and $T$ is the temperature. Molar volumes $\left(v^{V}\right.$ and $\left.v^{L}\right)$ and fugacity coefficients $\left(\varphi_{i}^{V}\right.$ and $\varphi_{i}^{L}$ of the vapor and liquid) were calculated with the equation of state.
Table 1

Strategies for modeling ILs.

\begin{tabular}{llllllll}
\hline & Molecule & Ions & $a^{\text {hc }}$ & $a^{\text {disp }}$ & $a^{\text {assoc }}$ & $a^{\text {polar }}$ & $a^{\text {ion }}$ \\
\hline Strategy 1 & $\sqrt{ }$ & & $\sqrt{ }$ & $\sqrt{ }$ & & & \\
Strategy 2 & $\sqrt{ }$ & & $\sqrt{ }$ & $\sqrt{ }$ & $\sqrt{ }$ & & \\
Strategy 3 & $\sqrt{ }$ & & $\sqrt{ }$ & $\sqrt{ }$ & & $\sqrt{ }$ & \\
Strategy 4 & & $\sqrt{ }$ & $\sqrt{ }$ & $\sqrt{ }$ & & & \\
Strategy 5 & & $\sqrt{ }$ & $\sqrt{ }$ & $\sqrt{ }$ & $\sqrt{ }$ & & \\
Strategy 6 & & $\sqrt{ }$ & $\sqrt{ }$ & $\sqrt{ }$ & & & $\sqrt{ }$ \\
\hline
\end{tabular}

As the vapor pressure of ILs is extremely low at temperatures up to $450 \mathrm{~K}$, it was assumed that the IL will not vaporize into the gas-rich phase. That is, the phase-equilibrium relations for single gas solubility in IL can be reduced to:

$\varphi_{j}^{V}\left(T, v^{V}\right)=x_{j} \varphi_{j}^{L}\left(T, v^{L}, x_{i}\right) \quad(j$ is a component other than IL)

yielding the gas solubility $x_{\mathrm{CO}_{2}}$ or $x_{\mathrm{CH}_{4}}$ in ILs.

Henry's constant is calculated with:

$H_{j, \mathrm{IL}}=\lim _{x_{j \rightarrow 0}}\left(\frac{P \varphi_{j}^{V}}{x_{j}}\right)$

\section{Strategies and assumptions for modeling ILs}

In this work, six strategies were considered to model densities of pure ILs and - based on this - to predict the gas solubility (Table 1). In all these strategies the hard-chain and dispersive forces between ions/ILs were taken into account. In strategies 1-3, ILs were modeled as non-dissociated, non-spherical molecules. The first strategy 1 was to model ILs without any specific interactions other than repulsive (hard-chain) and dispersion forces. In strategy 2, each IL was assigned two association sites, and association interaction was allowed between two different sites of two IL molecules. In strategy 3, ILs were modeled as non-associating but polar molecules, in which the polar interactions were represented as proposed by Gross et al. [27-29].

In contrast, in strategies 4-6 the ILs were treated as strong electrolytes which completely dissociate into cation and anion. Here, the simplest strategy 4 considers only dispersive attractions among the non-spherical ions. In strategy 5 , the association term was used to account for attractive interactions between the ions. Each ion was assigned one association site only. That is, only cross-association between anion and cation is allowed (no association among cations or among anions). In strategy 6, the Debye-Hückel (DH) theory was used to describe Coulomb forces among ions. The DH theory applied in this work is theoretically valid only for point charges (spherical species). As this work considers the ions as non-spherical, this leads to a theoretical inconsistency at a first glance. In order to apply the DH theory also to non-spherical molecules as in our work, one possibility is to neglect this inconsistency and to put the point charge on each molecule instead of each segment. Another possibility is to apply the model in a segmental approach where only one segment is charged whereas the others are not. In our work, based on the results (see Section 4), the first option was chosen. Further, it should be mentioned that the original DH theory was developed for dilute electrolyte solutions only. However, this theory applies also in the model for strategy 6 although the systems considered in this work are highly concentrated. The reason for this is that the DH term is used as only one contribution to the total Helmholtz energy of the system. That is, the system's energy is not totally determined by Debye-Hückel even not for the pure-IL state. Combined with other contributions, this is indeed an appropriate model as it partly captures the interionic forces due to charge. Note, that this model has been successfully applied so far to electrolyte solutions up to their solubility limit (not dilute at all). 
Table 2

The sources of pure-IL density data used for parameter fitting (pressure $p \leq 1000$ bar $)$.

\begin{tabular}{lll}
\hline ILs & Temperature range $(\mathrm{K})$ & Ref. \\
\hline$\left[\mathrm{C}_{2} \mathrm{mim}\right]\left[\mathrm{BF}_{4}\right]$ & $283-472$ & {$[34,35]$} \\
{$\left[\mathrm{C}_{4} \mathrm{mim}\right]\left[\mathrm{BF}_{4}\right]$} & $283-413$ & {$[34,36-42]$} \\
{$\left[\mathrm{C}_{6} \mathrm{mim}\right]\left[\mathrm{BF}_{4}\right]$} & $283-472$ & {$[34,35,43]$} \\
{$\left[\mathrm{C}_{8} \mathrm{mim}\right]\left[\mathrm{BF}_{4}\right]$} & $283-393$ & {$[34,40,44]$} \\
{$\left[\mathrm{C}_{2} \mathrm{mim}\right]\left[\mathrm{PF}_{6}\right]$} & $352-472$ & {$[35]$} \\
{$\left[\mathrm{C}_{4} \mathrm{mim}\right]\left[\mathrm{PF}_{6}\right]$} & $293-415$ & {$[36,39,45,46]$} \\
{$\left[\mathrm{C}_{6} \mathrm{mim}\right]\left[\mathrm{PF}_{6}\right]$} & $293-393$ & {$[40,45,47]$} \\
{$\left[\mathrm{C}_{8} \mathrm{mim}\right]\left[\mathrm{PF}_{6}\right]$} & $293-472$ & {$[35,40,45,47]$} \\
{$\left[\mathrm{C}_{2} \mathrm{mim}\right]\left[\mathrm{Tf}_{2} \mathrm{~N}\right]$} & $283-393$ & {$[48,49]$} \\
{$\left[\mathrm{C}_{4} \mathrm{mim}\right]\left[\mathrm{Tf}_{2} \mathrm{~N}\right]$} & $293-473$ & {$[36,50,51]$} \\
{$\left[\mathrm{C}_{6} \mathrm{mim}\right]\left[\mathrm{Tf}_{2} \mathrm{~N}\right]$} & $293-423$ & {$[52,53]$} \\
{$\left[\mathrm{C}_{8} \mathrm{mim}\right]\left[\mathrm{Tf}_{2} \mathrm{~N}\right]$} & $293-393$ & {$[48]$} \\
\hline
\end{tabular}

A parameter study for strategy 2 has shown that the best results for modeling the densities of some selected ILs were obtained by setting the association parameters at $\varepsilon^{\mathrm{AiBi}} / k_{B}=5000$ and $\kappa^{\mathrm{AiBi}}=0.1$. To make this comparable to literature work [11-14], this value was assumed to be constant for all the considered ILs. Similarly, the dipole moment for strategy 3 was set at $1.7 \mathrm{D}$ for all ILs as suggested, e.g. by Economou et al. [11,12]. To reduce the number of adjustable parameters in strategy 5 , we assumed that the association parameters between all pairs of cations and anions were the same as for methanol, which has also been used by Vega et al. $[13,14]$. Strategy 6 has not been investigated in the literature so far. Applying a Coulomb Helmholtz-energy term requires the relative dielectric constant of the respective medium accounting for shielding effects of the solvent. The absence of solvents in the pure ILs causes unperturbed and unshielded interionic forces; that is, the relative dielectric constant was set at unity (i.e. vacuum value) for all ILs.

\section{Results and discussion}

\subsection{Performance of the modeling strategies}

\subsubsection{Density modeling}

To obtain the ePC-SAFT parameters of ILs, the density data of pure ILs from the sources listed in Table 2 was used for fitting by all modeling strategies. The experimental data from the sources listed in Table 2 was measured at pressures lower than 1000 bar.

The fitting errors of the pure-IL density for different strategies are listed in Table 3 in which ARD is calculated by:

$\mathrm{ARD}=100 \frac{1}{\mathrm{NP}} \sum_{i=1}^{\mathrm{NP}}\left|1-\frac{\rho_{i}^{\mathrm{calc}}}{\rho_{i}^{\exp }}\right|$

where NP is the number of experimental data points, and the superscripts "calc" and "exp" are the calculation results and experimental data, respectively.

The results of strategy 6 will be discussed in detail, and the pureion parameters obtained for strategy 6 are given in Section 4.2.1. For completeness, the parameters obtained for strategies $1,2,4$, and 5 are listed in Tables S1-S4, respectively, as supplementary material. For strategy 3 (molecule-based model with polar interaction without association), the parameters are almost the same as those in strategy 1 which is therefore omitted in the parameter listing.
Table 4

PC-SAFT parameters for $\mathrm{CO}_{2}$ and $\mathrm{CH}_{4}$ [18] used in this work.

\begin{tabular}{llll}
\hline & $m_{\text {seg,i }}$ & $\sigma_{i}(\AA)$ & $u_{i} / k_{B}$ \\
\hline $\mathrm{CO}_{2}$ & 2.0727 & 2.7852 & 169.21 \\
$\mathrm{CH}_{4}$ & 1 & 3.7039 & 150.03 \\
\hline
\end{tabular}

The ARD results listed in Table 3 show that the fitting error in IL density of the ion-based strategies 4-6 is comparable, but slightly less than that of the molecule-based ones $1-3$. For example, modeling ILs with hard-chain repulsion and dispersion attraction forces only (molecular approach: strategy 1 , ion approach: strategy 4) leads to a deviation (ARD) from the experimental density of pure ILs of about $0.19 \%$ and $0.13 \%$, respectively. Interestingly, the consideration of additional interactions (associative or Coulomb forces) does not increase the model performance remarkably. Moreover, including polar interactions does not increase the model performance of the density description at all. This is due to the fact that the relatively high values of the segment diameter, segment number, and dispersion-energy parameter of the ILs induce a very small reduced dipolar moment making the polar term negligible compared to the other PC-SAFT energy contributions. Therefore, in the following part, the further investigation of strategy 3 was excluded.

\subsection{2. $\mathrm{CO}_{2}$ solubility prediction}

In addition to modeling pure ILs, the different strategies were applied for describing gas-IL mixtures. Based on the parameters obtained from fitting to pure-IL densities (Section 4.1.1) the $\mathrm{CO}_{2}$ solubility was then predicted for all strategies without any additional adjustable parameters. $\mathrm{CO}_{2}$ was modeled without quadruple interactions, and the model parameters were taken directly from the literature [18] (see Table 4). For the strategies 2 and 5, association sites were assigned to the IL-molecule or the IL-ions, respectively. Thus, self-association among ILs or ions is accounted for. For strategy 6 , the effect of $\mathrm{CO}_{2}$ on the dielectric constant of an IL solution was neglected, as the dielectric constant of pure $\mathrm{CO}_{2}$ is roughly unity.

To illustrate the $\mathrm{CO}_{2}$ solubility prediction in ILs with the different strategies, the results of $\left[\mathrm{C}_{6} \mathrm{mim}\right]\left[\mathrm{BF}_{4}\right]$ at $313 \mathrm{~K}$ and those of $\left[\mathrm{C}_{8} \mathrm{mim}\right]\left[\mathrm{Tf}_{2} \mathrm{~N}\right]$ at $345 \mathrm{~K}$ are shown in Fig. 1 . The model performance varies strongly for the different strategies. Generally, the prediction of the ion-based models is better than that of the molecule-based ones. Further, including the association or Debye-Hückel interaction greatly improves the $\mathrm{CO}_{2}$-solubility prediction. Obviously, the ion-based model including the Debye-Hückel term (strategy 6) presents the most quantitative approach, as it allows for a reliable prediction (no binary interaction parameter $k_{i j}$ ) of the $\mathrm{CO}_{2}$ solubility in ILs.

To improve the modeling results, usually the binary interaction parameter $k_{i j}$ in Eq. (4) is used to adjust cross-dispersion energies between IL-molecule and $\mathrm{CO}_{2}$ or IL-ion and $\mathrm{CO}_{2}$, respectively. Although correlating the data is not the focus of this work, investigations have shown that for the molecule-based models, IL-specific $k_{i j}$ values have to be used between $\mathrm{CO}_{2}$ and different ILs to achieve a quantitative description of $\mathrm{CO}_{2}$ solubility. Moreover, these $k_{i j} \mathrm{~S}$ depend on temperature. For the ion-based models, ion-specific temperature-independent $k_{i j}$ s should be used for $\mathrm{CO}_{2} /$ cation and $\mathrm{CO}_{2}$ /anion, respectively.

Table 3

ePC-SAFT fitting errors in density $(\rho)$ for the pure ILs listed in Table 2 according to Eq. (8).

\begin{tabular}{|c|c|c|c|c|c|c|}
\hline & Strategy 1 & Strategy 2 & Strategy 3 & Strategy 4 & Strategy 5 & Strategy 6 \\
\hline$(\mathrm{ARD})_{\rho}(\%)$ & 0.19 & 0.15 & 0.19 & 0.13 & 0.11 & 0.14 \\
\hline
\end{tabular}



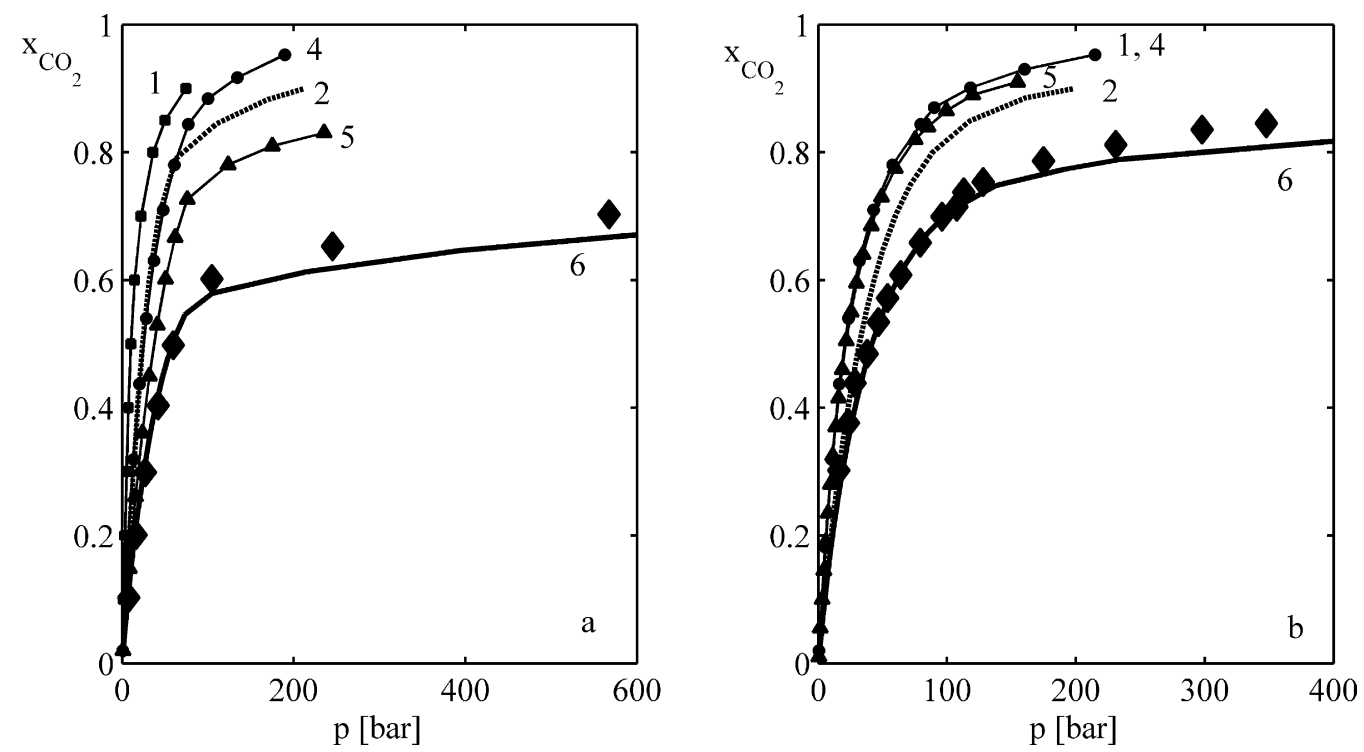

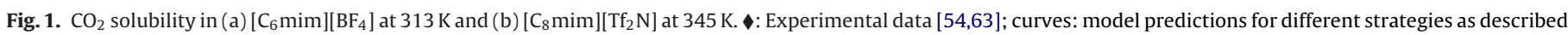
in Table $1 . \mathbf{\square}$, strategy $1 ; \ldots$, strategy $2 ; \bullet$, strategy $4 ; \boldsymbol{\Lambda}$, strategy $5 ;-$, strategy 6.

In contrast, the use of any binary interaction parameter between ion and $\mathrm{CO}_{2}$ is not required for strategy 6 . That is, pure predictions are possible by accounting for Coulomb interactions among the IL-ions. Prediction in this context means that the ion parameters are fitted to pure-IL density data only and are not trained to any mixture $\left(\mathrm{CO}_{2} / \mathrm{IL}\right)$ properties. Thus, modeling ILs with accounting for Coulomb forces is highly recommended.

\subsection{Ion-based modeling accounting for Coulomb interactions}

As shown in the previous section, modeling ILs with an ion-based strategy including a Debye-Hückel term allows for quantitatively predicting ( no $k_{i j}$ ) $\mathrm{CO}_{2}$ solubility in the considered ILs. The detailed results are presented in this section.

\subsubsection{IL parameters}

Ion parameters (segment number $m_{\text {seg,i }}$, segment diameter $\sigma_{i}$, and dispersion-energy parameter $u_{i} / k_{B}$ of $\left[\mathrm{C}_{2} \mathrm{mim}\right]^{+}$, $\left[\mathrm{C}_{4} \mathrm{mim}\right]^{+},\left[\mathrm{C}_{6} \mathrm{mim}\right]^{+},\left[\mathrm{C}_{8} \mathrm{mim}\right]^{+},\left[\mathrm{BF}_{4}\right]^{-},\left[\mathrm{PF}_{6}\right]^{-}$, and $\left[\mathrm{Tf}_{2} \mathrm{~N}\right]^{-}$) were obtained from fitting simultaneously to reliable density data of $\left[C_{n} \mathrm{mim}\right]\left[\mathrm{BF}_{4}\right],\left[\mathrm{C}_{n} \mathrm{mim}\right]\left[\mathrm{PF}_{6}\right],\left[C_{n} \mathrm{mim}_{[}\right]\left[\mathrm{Tf}_{2} \mathrm{~N}\right], n=2,4,6,8$ measured at temperatures from 283 to $473 \mathrm{~K}$ and at pressures up to $1000 \mathrm{bar}$ (Refs. given in Table 2). These parameters are listed in Table 5. The fitting error in density for all ILs is only $0.14 \%$ on average.

For cations, the segment number, segment diameter, and dispersion-energy parameter increase with increasing molecular weight. They can also be correlated linearly as shown in Fig. 2. For anions, the segment number and segment diameter increase with increasing molecular weight. However, at the same time the dispersion-energy parameter decreases and does not depend linearly on the molecular weight. In general, the dispersion-energy parameter of anions is much bigger than that of cations; for $\left[\mathrm{Tf}_{2} \mathrm{~N}\right]^{-}$ the value of $u_{i} / k_{B}$ is much smaller than those of $\left[\mathrm{BF}_{4}\right]^{-}$and $\left[\mathrm{PF}_{6}\right]^{-}$.

Using these parameters for the ions allows calculating the Helmholtz energy contributions of each term. These energy contributions (hard chain, dispersion, and ionic) are - absolutely - in the same order of magnitude. This is very different compared to models (e.g. ePC-SAFT, SAFT1) describing "usual" electrolyte systems (e.g. $1 \mathrm{~m} \mathrm{NaCl}$ /water) where the ionic term is usually much lower than the other contributions.

\subsubsection{IL-density prediction up to 3000 bar}

Density is an important property of a substance. Knowledge of it is needed for example in design problems, sizing of storage vessels, and in liquid metering calculations. Recently, new applications of ILs as lubricants have been proposed, in which the viscosity at very high pressures is one of the important factors. As viscosity directly depends on density, a reliable model for the prediction of density up to high pressures is required.

Due to the limited availability of experimental density data at pressures higher than $1000 \mathrm{bar}$, the ePC-SAFT parameters were fitted to the experimental density data from sources in which the densities were measured at pressures not higher than 1000 bar. For some imidazolium-based ILs, density data up to 3000 bar are also available from sources listed in Table 6 . These high-pressure data were excluded from the parameter fitting.

To investigate the model performance, the model prediction was compared with the available experimental data up to high pressures (>1000 bar). For $\mathrm{BF}_{4}$-imidazolium-based ILs, the model predicts the density in very good agreement (ARD less than $0.31 \%$ ) for $\left[\mathrm{C}_{2} \mathrm{mim}\right]\left[\mathrm{BF}_{4}\right],\left[\mathrm{C}_{4} \mathrm{mim}\right]\left[\mathrm{BF}_{4}\right]$, and $\left[\mathrm{C}_{6} \mathrm{mim}\right]\left[\mathrm{BF}_{4}\right]$. The comparison

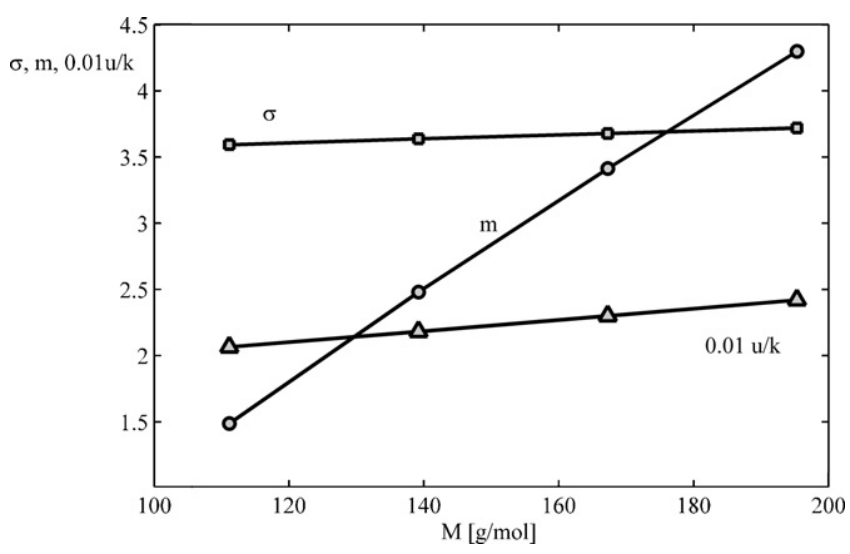

Fig. 2. ePC-SAFT parameters for the cations $\left[C_{2} \mathrm{mim}\right]^{+},\left[\mathrm{C}_{4} \mathrm{mim}\right]^{+},\left[\mathrm{C}_{6} \mathrm{mim}\right]^{+}$, and $\left[\mathrm{C}_{8} \mathrm{mim}\right]^{+}$for strategy 6 (ion-based model with Coulomb interactions) as function of molecular weight. $\square$, segment diameter $\sigma_{i} ; \bigcirc$, segment number $m_{\text {seg, },} ; \triangle$, dispersionenergy parameter $0.01 u_{i} / k_{B}$; lines are linear parameter correlations. 
Table 5

Parameters for IL-ions in strategy 6 (ion-based model with Coulomb interactions).

\begin{tabular}{|c|c|c|c|c|c|c|c|}
\hline Ion & {$\left[\mathrm{C}_{2} \mathrm{mim}\right]^{+}$} & {$\left[\mathrm{C}_{4} \mathrm{mim}\right]^{+}$} & {$\left[\mathrm{C}_{6} \mathrm{mim}\right]^{+}$} & {$\left[\mathrm{C}_{8} \mathrm{mim}\right]^{+}$} & {$\left[\mathrm{BF}_{4}\right]^{-}$} & {$\left[\mathrm{PF}_{6}\right]^{-}$} & {$\left[\mathrm{Tf}_{2} \mathrm{~N}\right]^{-}$} \\
\hline$m_{\text {seg,i }}$ & 1.4872 & 2.4805 & 3.4131 & 4.2977 & 3.8227 & 4.2771 & 6.0103 \\
\hline$\sigma_{i}(\AA)$ & 3.5926 & 3.6371 & 3.6781 & 3.7187 & 3.5088 & 3.5889 & 3.7469 \\
\hline$u_{i} / k_{B}(\mathrm{~K})$ & 206.49 & 218.144 & 230.00 & 242.00 & 496.12 & 492.28 & 375.65 \\
\hline
\end{tabular}
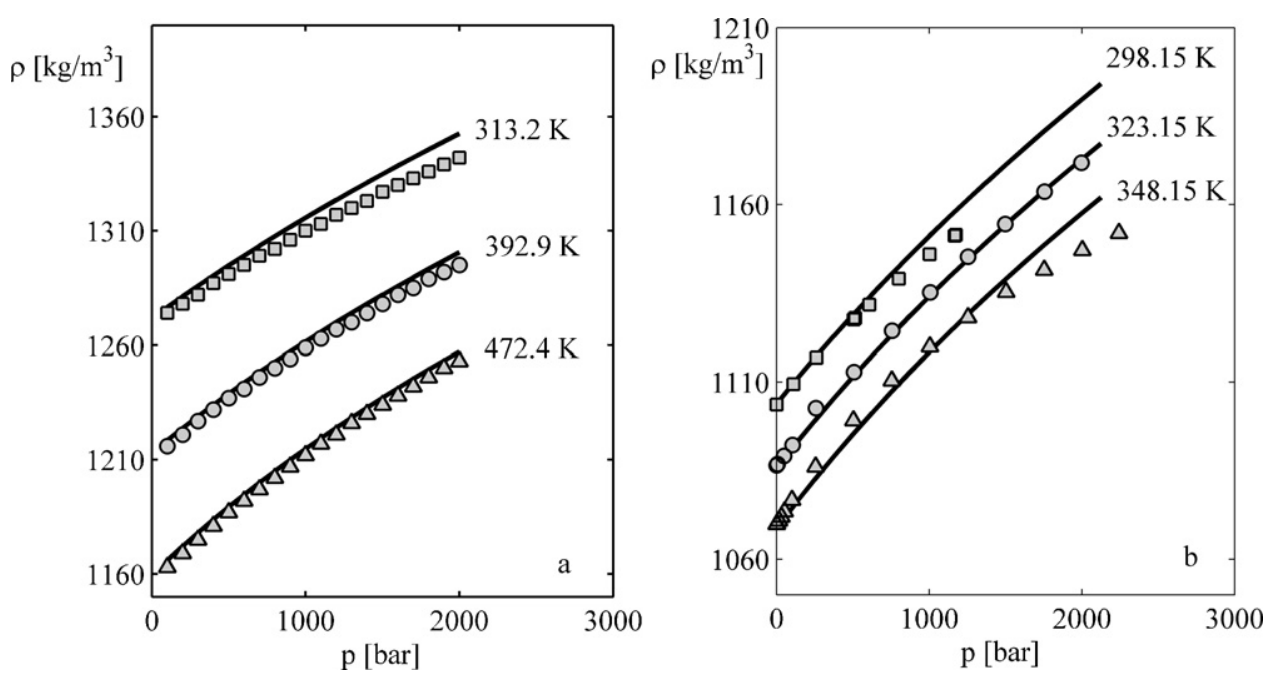

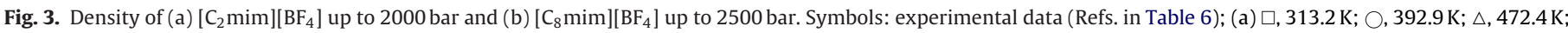
(b) $\square, 298.15 \mathrm{~K} ; \bigcirc, 323.15 \mathrm{~K} ; \triangle, 348.15 \mathrm{~K}$. Curves: model prediction with parameters listed in Table 5.

for $\left[\mathrm{C}_{2} \mathrm{mim}\right]\left[\mathrm{BF}_{4}\right]$ is shown in Fig. 3a as a typical illustration of the model performance.

For $\left[\mathrm{C}_{8} \mathrm{mim}\right]\left[\mathrm{BF}_{4}\right]$, the experimental data was measured by the research group of Harris between 298 and $348 \mathrm{~K}$ [44]. At pressures up to 1500 bar, the model prediction agrees very well with experimental data as shown in Fig. 3b. At higher pressures, the model over-predicts the experimental data at $348 \mathrm{~K}$ but is in good agreement at $323 \mathrm{~K}$. Since the model predictions agree with experimental data for $\left[\mathrm{C}_{2} \mathrm{mim}\right]\left[\mathrm{BF}_{4}\right],\left[\mathrm{C}_{4} \mathrm{mim}\right]\left[\mathrm{BF}_{4}\right]$, and $\left[\mathrm{C}_{6} \mathrm{mim}\right]\left[\mathrm{BF}_{4}\right]$ in the whole temperature and pressure range, the experimental data of Harris [44] for $\left[\mathrm{C}_{8} \mathrm{mim}\right]\left[\mathrm{BF}_{4}\right]$ at $348 \mathrm{~K}$ and at pressures higher than 1500 bar may not be as accurate as the other data points.

For $\mathrm{PF}_{6}$-imidazolium-based ILs, the model prediction agrees well with the experimental data determined by the research group of Smith at pressures up to 2000 bar [35,57]. However, at high pressures the data from other sources is lower than the model prediction as well as the experimental data of Smith [35,57]. For example, for $\left[\mathrm{C}_{4} \mathrm{mim}\right]\left[\mathrm{PF}_{6}\right]$ experimental data exists from three sources, namely Gu and Brennecke [58], Smith's group [57], and Harris et al. [59]. As shown in Fig. 4a, discrepancies between model prediction and the experimental data of Gu and Brennecke [58] and Harris et al. [59] are observed at pressures higher than 1000 bar for

Table 6

ARDs of the ePC-SAFT predicted pure-IL densities with respect to the experimental data up to 3000 bar.

\begin{tabular}{lllll}
\hline & $T(\mathrm{~K})$ & $p^{\max }($ bar) & Ref. & $(\mathrm{ARD})_{\rho}(\%)$ \\
\hline$\left[\mathrm{C}_{2} \mathrm{mim}\right]\left[\mathrm{BF}_{4}\right]$ & $313-472$ & 2000 & {$[35]$} & 0.31 \\
{$\left[\mathrm{C}_{4} \mathrm{mim}\right]\left[\mathrm{BF}_{4}\right]$} & $283-472$ & 3000 & {$[55-57]$} & 0.26 \\
{$\left[\mathrm{C}_{6} \mathrm{mim}\right]\left[\mathrm{BF}_{4}\right]$} & $298-473$ & 2000 & {$[35,43]$} & 0.13 \\
{$\left[\mathrm{C}_{8} \mathrm{mim}\right]\left[\mathrm{BF}_{4}\right]$} & $298.2-348.15$ & 2242 & {$[44]$} & 0.42 \\
{$\left[\mathrm{C}_{2} \mathrm{mim}\right]\left[\mathrm{PF}_{6}\right]$} & $373-473$ & 2000 & {$[35]$} & 0.12 \\
{$\left[\mathrm{C}_{4} \mathrm{mim}\right]\left[\mathrm{PF}_{6}\right]$} & $298.2-472.3$ & 2493 & {$[57-59]$} & 0.24 \\
{$\left[\mathrm{C}_{6} \mathrm{mim}\right]\left[\mathrm{PF}_{6}\right]$} & $298.15-472.3$ & 2385 & {$[35,60]$} & 0.19 \\
{$\left[\mathrm{C}_{8} \mathrm{mim}\right]\left[\mathrm{PF}_{6}\right]$} & $298.15-472.3$ & 2042 & {$[35,44,58]$} & 0.22 \\
{$\left[\mathrm{C}_{2} \mathrm{mim}\right]\left[\mathrm{Tf}_{2} \mathrm{~N}\right]$} & $283.19-373.14$ & 1000 & {$[49]$} & 0.18 \\
{$\left[\mathrm{C}_{4} \mathrm{mim}\right]\left[\mathrm{Tf}_{2} \mathrm{~N}\right]$} & $283.15-348.15$ & 3000 & {$[60]$} & 0.39
\end{tabular}

$\left[\mathrm{C}_{4} \mathrm{mim}\right]\left[\mathrm{PF}_{6}\right]$. A similar observation is also found for $\left[\mathrm{C}_{6} \mathrm{mim}\right]\left[\mathrm{PF}_{6}\right]$ at $313 \mathrm{~K}$ (Fig. $4 \mathrm{~b}$ ). For $\left[\mathrm{C}_{8} \mathrm{mim}\right]\left[\mathrm{PF}_{6}\right]$, the experimental data from different sources is consistent, and the model prediction agrees well with all the experimental data, and the deviation is $0.22 \%$ on average.

For $\left[\mathrm{C}_{2} \mathrm{mim}\right]\left[\mathrm{Tf}_{2} \mathrm{~N}\right]$, the model prediction agrees with the experimental data that was determined by the research group of Safarov [49], the error is $0.18 \%$ on average. In the case of $\left[\mathrm{C}_{4} \mathrm{mim}\right]\left[\mathrm{Tf}_{2} \mathrm{~N}\right]$, it is slightly higher (0.39\%). It was found that at pressures higher than 2250 bar and at $323.15 \mathrm{~K}$, the experimental densities determined by the research group of Harris [60] are lower than those at $348.15 \mathrm{~K}$, which is obviously wrong. In Fig. $3 \mathrm{~b}$ it is shown that at high pressures the experimental data of Harris [44] for $\left[\mathrm{C}_{8} \mathrm{mim}\right]\left[\mathrm{BF}_{4}\right]$ is not accurate. All this implies that the accuracy of the experimental data of Harris [60] at high pressures is questionable. For $\left[\mathrm{C}_{6} \operatorname{mim}\right]\left[\mathrm{Tf}_{2} \mathrm{~N}\right]$ and $\left[\mathrm{C}_{8} \mathrm{mim}\right]\left[\mathrm{Tf}_{2} \mathrm{~N}\right]$, no experimental data at pressures higher than 1000 bar is available.

To summarize the model prediction for the density of pure ILs up to high pressure ( 3000 bar), the ARDs between the available experimental data and model predictions are listed in Table 6 for all ILs. As a result it can be concluded that ePC-SAFT can be used to extrapolate the density to the high-pressure regions for all the studied ILs, and some of the experimental data of the research group of Harris $[44,60]$ may not be as accurate as others.

\subsection{3. $\mathrm{CO}_{2}$ solubility prediction}

Applying the ion-based ePC-SAFT including a Debye-Hückel term with parameters listed in Tables 4, 5 and 7 also allows predicting the $\mathrm{CO}_{2}$ solubility in ILs. To evaluate the model performance, available experimental data was used to verify the model prediction.

4.2.3.1. Solubility at low pressures. First, the evaluation was performed for pressures lower than 20 bar. At pressures below 20 bar, the $\mathrm{CO}_{2}$ solubility was measured in $\left[\mathrm{C}_{2}\right.$ mim] $\left[\mathrm{Tf}_{2} \mathrm{~N}\right][61,62]$, $\left[\mathrm{C}_{4} \mathrm{mim}\right]\left[\mathrm{BF}_{4}\right][62-64],\left[\mathrm{C}_{4} \mathrm{mim}\right]\left[\mathrm{PF}_{6}\right][61,63-66],\left[\mathrm{C}_{4} \mathrm{mim}\right]\left[\mathrm{Tf}_{2} \mathrm{~N}\right]$ 

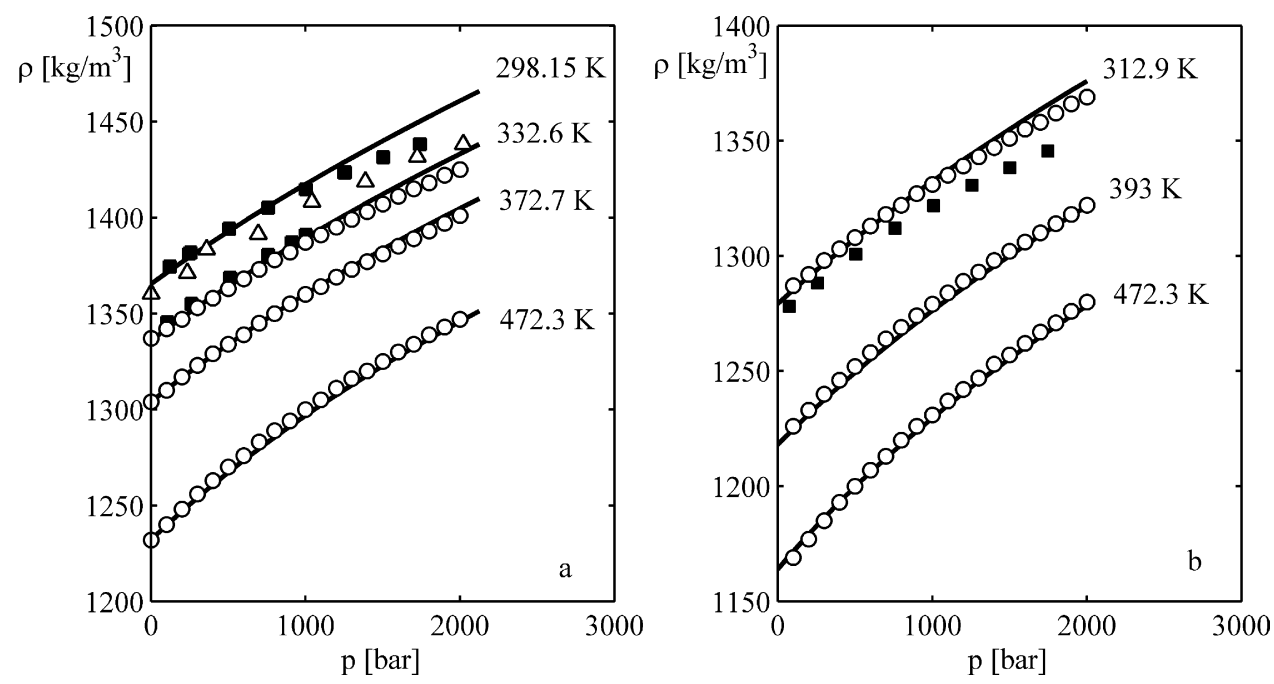

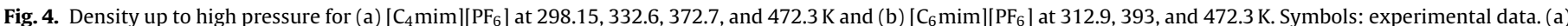

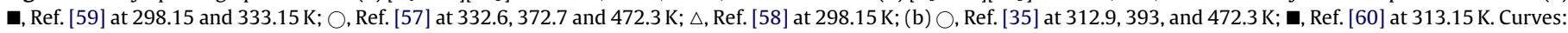
model prediction with parameters listed in Table 5.

Table 7

Binary interaction parameters $k_{i j}$ between gas and ion.

\begin{tabular}{|c|c|c|c|c|c|c|c|}
\hline & {$\left[\mathrm{C}_{2} \mathrm{mim}\right]^{+}$} & {$\left[\mathrm{C}_{4} \mathrm{mim}\right]^{+}$} & {$\left[\mathrm{C}_{6} \mathrm{mim}\right]^{+}$} & {$\left[\mathrm{C}_{8} \mathrm{mim}\right]^{+}$} & {$\left[\mathrm{BF}_{4}\right]^{-}$} & {$\left[\mathrm{PF}_{6}\right]^{-}$} & {$\left[\mathrm{Tf}_{2} \mathrm{~N}\right]^{-}$} \\
\hline $\mathrm{CO}_{2}$ & 0 & 0 & 0 & 0 & 0 & 0 & 0 \\
\hline $\mathrm{CH}_{4}$ & 0 & 0 & 0 & 0 & 0 & 0 & -0.09 \\
\hline
\end{tabular}

[63], [ $\left.\mathrm{C}_{6} \mathrm{mim}\right]\left[\mathrm{BF}_{4}\right][61],\left[\mathrm{C}_{6} \mathrm{mim}\right]\left[\mathrm{PF}_{6}\right][61]$, and $\left[\mathrm{C}_{6} \mathrm{mim}\right]\left[\mathrm{Tf}_{2} \mathrm{~N}\right]$ $[2,8,61,67]$ at temperatures in the range of $283-348 \mathrm{~K}$. Fig. 5a illustrates the comparison of the model prediction and the experimental $\mathrm{CO}_{2}$ solubility in $\left[\mathrm{C}_{4} \mathrm{mim}\right]\left[\mathrm{PF}_{6}\right]$. The model prediction agrees very well with the $\mathrm{CO}_{2}$ solubility data from different sources. Henry constants of $\mathrm{CO}_{2}$ in $\left[\mathrm{C}_{4} \mathrm{mim}\right]\left[\mathrm{PF}_{6}\right]$ were calculated and compared with available experimental data $[3,62,65,66,68,69]$. This is shown in Fig. 5b. The uncertainty of experimental Henry constants of $\mathrm{CO}_{2} /$ IL can be estimated at $\pm 10 \%$ at maximum [66], and the model shows a reliable prediction. The comparison of model prediction and experimental $\mathrm{CO}_{2}$ solubility in $\left[\mathrm{C}_{4} \mathrm{mim}\right]\left[\mathrm{BF}_{4}\right],\left[\mathrm{C}_{6} \mathrm{mim}\right]\left[\mathrm{BF}_{4}\right]$, and $\left[\mathrm{C}_{6} \mathrm{mim}\right]\left[\mathrm{PF}_{6}\right]$ is similar to that in $\left[\mathrm{C}_{4} \mathrm{mim}\right]\left[\mathrm{PF}_{6}\right]$, i.e. the model prediction also agrees well with all the experimental data.

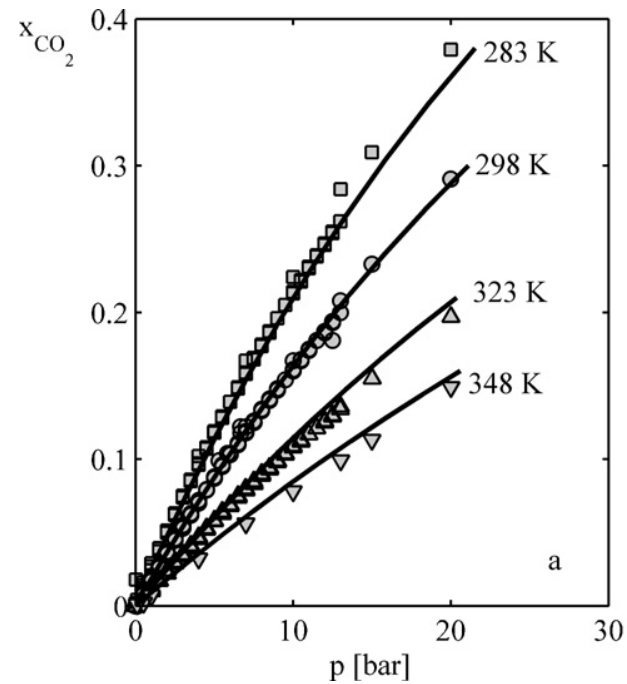

For $\mathrm{Tf}_{2} \mathrm{~N}$-based ILs at pressures lower than 20 bar, the model slightly overestimates the $\mathrm{CO}_{2}$ solubility, and the predicted Henry constants for $\mathrm{CO}_{2} /\left[\mathrm{C}_{n} \operatorname{mim}\right]\left[\mathrm{Tf}_{2} \mathrm{~N}\right]$ are lower than the experimental results. The adjustment of $k_{i j}$ can improve the model results at pressures lower than 20 bar. Setting $k_{\mathrm{CO}_{2}-\mathrm{Tf}_{2} \mathrm{~N}=}=$ -0.01 , the model can represent the $\mathrm{CO}_{2}$ solubility at low pressures with good accuracy for all $\mathrm{Tf}_{2} \mathrm{~N}$-based ILs $\left(\left[\mathrm{C}_{2} \operatorname{mim}\right]\left[\mathrm{Tf}_{2} \mathrm{~N}\right]\right.$, $\left[\mathrm{C}_{4} \mathrm{mim}\right]\left[\mathrm{Tf}_{2} \mathrm{~N}\right]$, and $\left.\left[\mathrm{C}_{6} \mathrm{mim}\right]\left[\mathrm{Tf}_{2} \mathrm{~N}\right]\right)$. However, in this strategy it slightly underestimates the $\mathrm{CO}_{2}$ solubility at high pressures $(\gg 20$ bar, for results, see next section and Fig. 6b). The results of $\mathrm{CO}_{2}$ solubility in $\left[\mathrm{C}_{2} \mathrm{mim}\right]\left[\mathrm{Tf}_{2} \mathrm{~N}\right]$ are shown in Fig. 6 to illustrate the model performance with or without using an adjustable $k_{i j}$. For the sake of completeness, the $k_{i j}$ values applied in

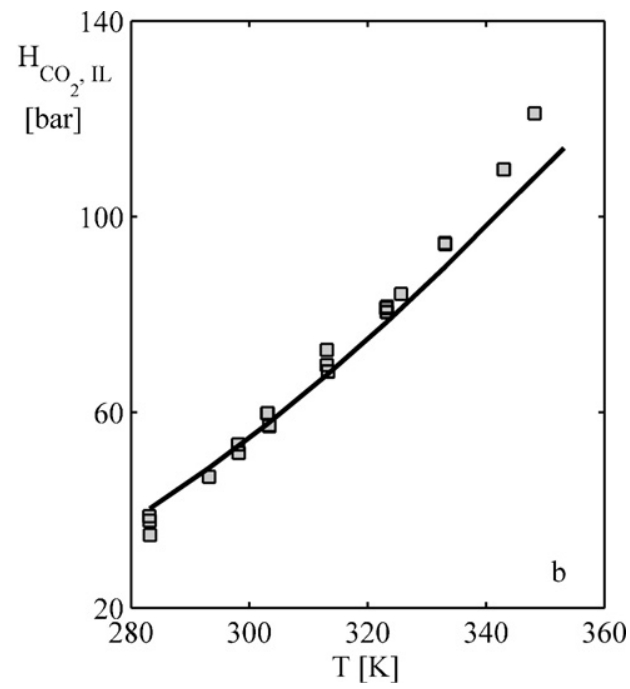

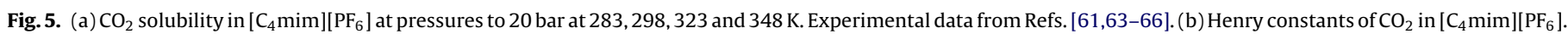
Experimental data from Refs. $[3,62,65,66,68,69]$. Symbols are experimental data; curves are model predictions with parameters listed in Tables 4,5 and 7. 

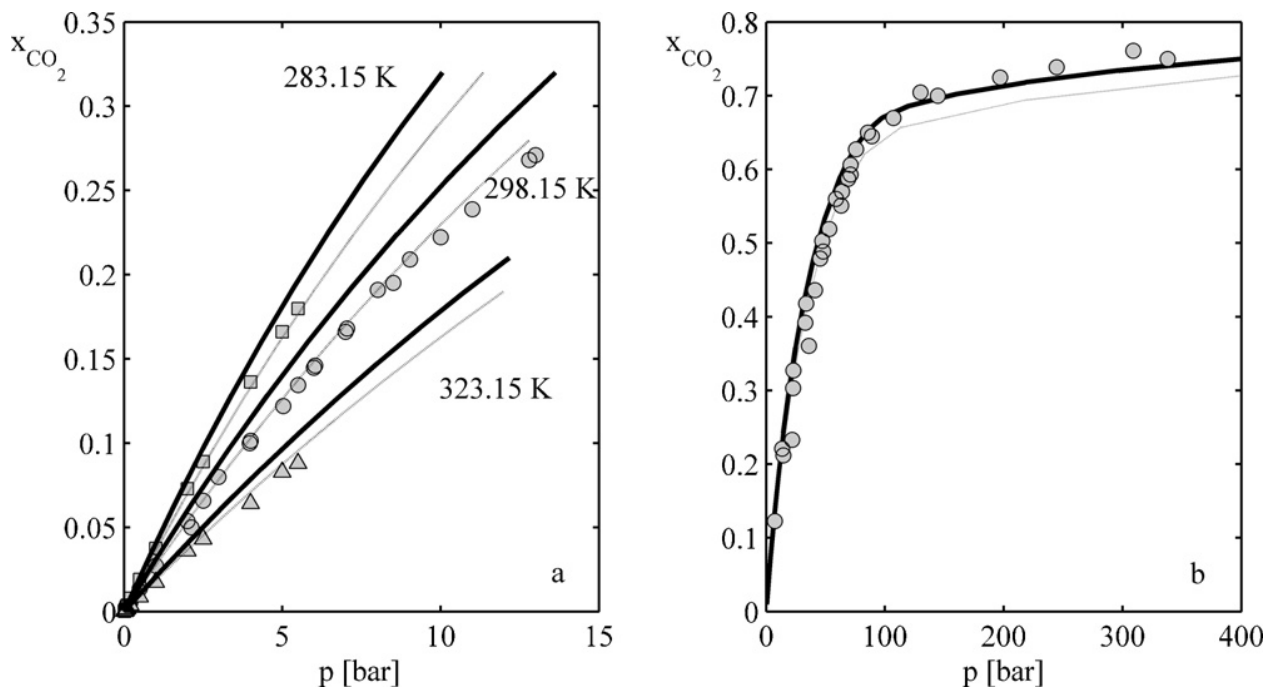

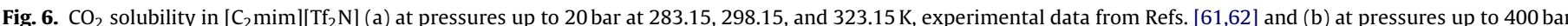

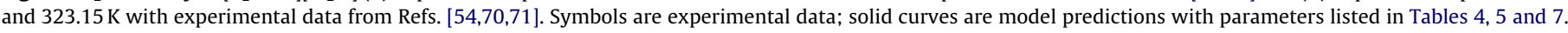
Dashed curves are model results with parameters listed in Tables 4 and 5 and $k_{\mathrm{CO}_{2}-\mathrm{Tf}_{2} \mathrm{~N}}=-0.01$.

this work are given in Table 7 for all considered IL/solvent combinations.

4.2.3.2. Solubility at high pressures. As shown in the last section, the $\mathrm{CO}_{2}$ solubility depends almost linearly on the system pressure in the low-pressure region. Thus, modeling the $\mathrm{CO}_{2}$ solubility at low pressures is not a real benchmark for a thermodynamic approach. In contrast, modeling the $\mathrm{CO}_{2}$ solubility in a wide pressure range is more challenging as the mole fraction of $\mathrm{CO}_{2}$ can vary from very small values up to more than 0.8 in mole fraction. As the focus of this work is to represent the $\mathrm{CO}_{2}$ solubility in a large pressure range, this section shows modeling results for pressures up to 1000 bar. The considered systems, the temperature range, the maximum pressure, as well as the respective sources of experimental data are listed in Table 8.

Fig. 7 exemplifies the comparison between ePC-SAFT predicted and experimental $\mathrm{CO}_{2}$ solubility data in $\left[\mathrm{C}_{8} \mathrm{mim}\right]\left[\mathrm{BF}_{4}\right]$ at two temperatures and at pressures up to 600 bar. With increasing temperature, the $\mathrm{CO}_{2}$ solubility decreases at low pressure, whereas this difference diminishes at higher pressures. At constant

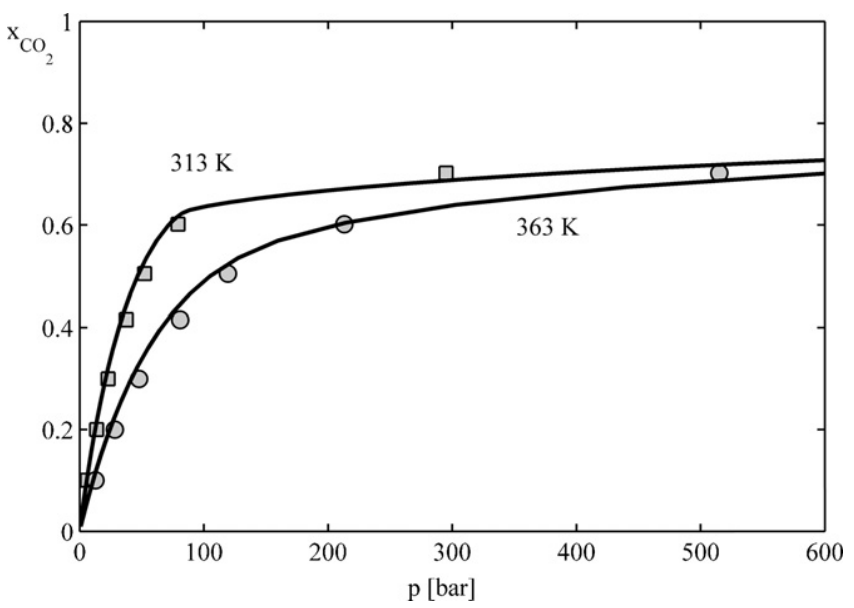

Fig. 7. $\mathrm{CO}_{2}$ solubility in $\left[\mathrm{C}_{8} \mathrm{mim}\right]\left[\mathrm{BF}_{4}\right]$ at $313 \mathrm{~K}$ and $363 \mathrm{~K}$. Curves: model prediction with the parameters listed in Tables 4, 5 and 7; symbols: experimental data (see Refs. in Table 8), $\square$ at $313 \mathrm{~K} ; \bigcirc$ at $363 \mathrm{~K}$. temperature and with increasing pressure, the $\mathrm{CO}_{2}$ solubility increases strongly, while further pressurization ( $>300$ bar for $\left.\left[\mathrm{C}_{8} \mathrm{mim}\right]\left[\mathrm{BF}_{4}\right]\right)$ only slightly affects the solubility. This is due to the properties of the gas-rich phase (pure $\mathrm{CO}_{2}$ ): at high pressures, the $\mathrm{CO}_{2}$ phase is very dense, and the effect of pressure on dense fluids is known to be much less pronounced than on low-density gases. Without using any adjustable parameters, i.e. setting $k_{i j}$ at zero, the model can be used to predict quantitatively the effects of temperature and pressure on the $\mathrm{CO}_{2}$ solubility.

Fig. 8a illustrates the prediction of the $\mathrm{CO}_{2}$ solubility in $\left[\mathrm{C}_{\mathrm{n}} \mathrm{mim}\right]\left[\mathrm{PF}_{6}\right]$ compared to the experimental data at pressures up to 800 bar. The effects of temperature and pressure on the $\mathrm{CO}_{2}$ solubility are similar to those in $\left[\mathrm{C}_{n} \mathrm{mim}\right]\left[\mathrm{BF}_{4}\right]$ systems. As shown in Fig. 8a, the $\mathrm{CO}_{2}$ solubility increases with increasing length of alkyl substituents, especially at high pressures. Obviously, their influence is much more significant than the effects of temperature and pressure. Without any adjustable parameters $\left(k_{i j}=0\right)$ the model again captures the effect of temperature, pressure, and the length of alkyls in ILs on the $\mathrm{CO}_{2}$ solubility quantitatively.

Fig. $8 \mathrm{~b}$ shows the modeling results of the $\mathrm{CO}_{2} /\left[\mathrm{C}_{2} \operatorname{mim}\right]\left[\mathrm{Tf}_{2} \mathrm{~N}\right]$ system up to 400 bar. Compared to $\mathrm{BF}_{4}$ - and $\mathrm{PF}_{6}$-based ILs, the $\mathrm{CO}_{2}$ solubility in $\mathrm{Tf}_{2} \mathrm{~N}$-based ILs is much higher at elevated pressures. As shown in Table 5, the dispersion-energy parameter of $\left[\mathrm{Tf}_{2} \mathrm{~N}\right]^{-}$is comparatively low, thereby reducing the attractive interaction between this anion and the cations. Thus, $\mathrm{CO}_{2}$ can more easily break the cation/anion forces. Again, the model prediction agrees well with the experimental data and represents the effect of temperature, pressure, and anions on $\mathrm{CO}_{2}$ solubility reliably.

As mentioned before, many SAFT-based models have been applied to describe the $\mathrm{CO}_{2}$ solubility in ILs up to elevated pressures. The model of Economou's group was used for $\mathrm{BF}_{4}-$ and $\mathrm{PF}_{6}$-based ILs, the models of Vega's group and of Ji and Adidharma for $\mathrm{BF}_{4}$ - and $\mathrm{PF}_{6}{ }^{-}$and $\mathrm{Tf}_{2} \mathrm{~N}$-based ILs. In all these approaches, binary parameters were used to correct the cross-dispersion energy between $\mathrm{CO}_{2}$ and IL. In this work, without any additional parameters, the model predicts the $\mathrm{CO}_{2}$ solubility in all ILs quantitatively in a wide temperature and pressure range, and the model's accuracy is within the experimental uncertainty. This can be seen also from Table 8 , which summarizes the ARD values of the ePC-SAFT predicted $\mathrm{CO}_{2}$ solubilities in ILs. 
Table 8

Experimental data sources for $\mathrm{CO}_{2}$ solubility in $\left[\mathrm{C}_{n} \mathrm{mim}\right]\left[\mathrm{BF}_{4}\right],\left[\mathrm{C}_{n} \mathrm{mim}\right]\left[\mathrm{PF}_{6}\right]$, and $\left[\mathrm{C}_{n} \mathrm{mim}\right]\left[\mathrm{Tf} f_{2} \mathrm{~N}\right]$ and ePC-SAFT prediction deviations in $\mathrm{CO}_{2}$ solubility.

\begin{tabular}{|c|c|c|c|c|}
\hline & Temperature range $(\mathrm{K})$ & $p^{\max }$ (bar) & Ref. & $(\mathrm{ARD}) x_{\mathrm{CO}_{2}}$ \\
\hline$\left[\mathrm{C}_{2} \mathrm{mim}\right]\left[\mathrm{BF}_{4}\right]$ & 298.15-313.2 & 41 & {$[61,72]$} & 7.7 \\
\hline$\left[\mathrm{C}_{4} \mathrm{mim}\right]\left[\mathrm{BF}_{4}\right]$ & $278.47-383.15$ & 677 & {$[64,73-75]$} & 5.5 \\
\hline$\left[\mathrm{C}_{6} \mathrm{mim}\right]\left[\mathrm{BF}_{4}\right]$ & $293.18-368.16$ & 866 & {$[61,76,77]$} & 5.1 \\
\hline$\left[\mathrm{C}_{8} \mathrm{mim}\right]\left[\mathrm{BF}_{4}\right]$ & $307.79-363.29$ & 858 & {$[78]$} & 5.6 \\
\hline$\left[\mathrm{C}_{2} \mathrm{mim}\right]\left[\mathrm{PF}_{6}\right]$ & $313.01-366.03$ & 971 & [79] & 3.6 \\
\hline$\left[\mathrm{C}_{4} \mathrm{mim}\right]\left[\mathrm{PF}_{6}\right]$ & 293.55-395.05 & 735 & {$[80-84]$} & 6.1 \\
\hline$\left[\mathrm{C}_{6} \mathrm{mim}\right]\left[\mathrm{PF}_{6}\right]$ & $298.31-363.58$ & 946 & {$[85]$} & 6.1 \\
\hline$\left[\mathrm{C}_{2} \mathrm{mim}\right]\left[\mathrm{Tf}_{2} \mathrm{~N}\right]$ & $292.16-450.49$ & 479 & {$[54,70,71]$} & 7.6 \\
\hline$\left[\mathrm{C}_{4} \mathrm{mim}\right]\left[\mathrm{Tf}_{2} \mathrm{~N}\right]$ & $279.98-449.41$ & 500 & {$[54,75,86-89]$} & 8.1 \\
\hline$\left[\mathrm{C}_{6} \mathrm{mim}\right]\left[\mathrm{Tf}_{2} \mathrm{~N}\right]$ & $293.15-413.2$ & 390 & {$[54,90,91]$} & 7.7 \\
\hline$\left[\mathrm{C}_{8} \mathrm{mim}\right]\left[\mathrm{Tf}_{2} \mathrm{~N}\right]$ & $298.25-344.55$ & 348 & [54] & 4.3 \\
\hline
\end{tabular}
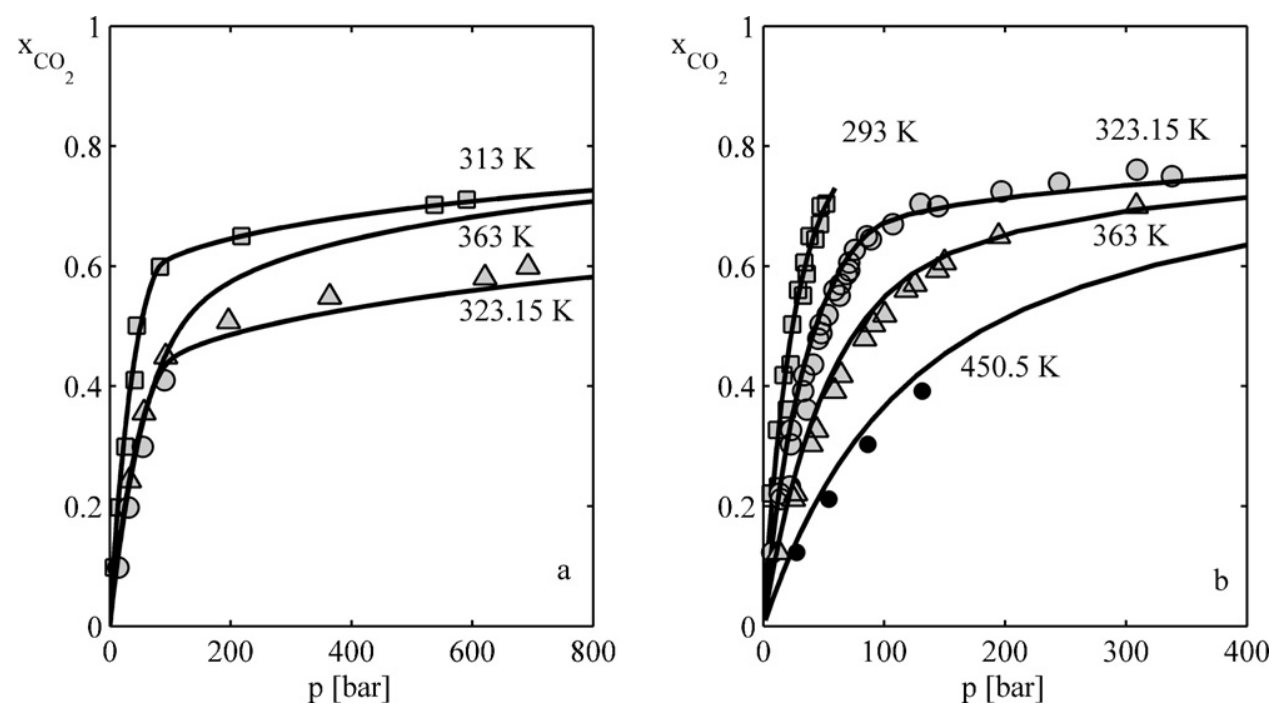

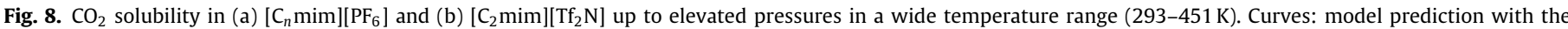

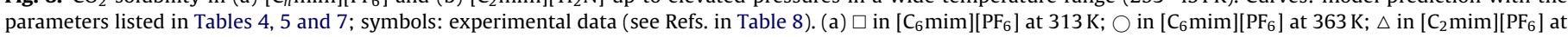
$323.15 \mathrm{~K}$. (b) $\square, 293 \mathrm{~K} ; \bigcirc, 323.15 \mathrm{~K} ; \Delta, 363 \mathrm{~K} ; \bullet$, $450.5 \mathrm{~K}$.

\subsection{4. $\mathrm{CH}_{4}$ solubility prediction}

The $\mathrm{CH}_{4}$ solubility in $\left[\mathrm{C}_{4} \mathrm{mim}\right]\left[\mathrm{Tf}_{2} \mathrm{~N}\right],\left[\mathrm{C}_{6} \operatorname{mim}\right]\left[\mathrm{Tf}_{2} \mathrm{~N}\right]$ and $\left[\mathrm{C}_{4} \mathrm{mim}\right]\left[\mathrm{PF}_{6}\right]$ is also accessible from the open literature $[65,92,93]$. In general, the $\mathrm{CH}_{4}$ solubility in ILs is much lower than the $\mathrm{CO}_{2}$ solubility. This is shown exemplarily for $\left[\mathrm{C}_{4} \mathrm{mim}\right]\left[\mathrm{PF}_{6}\right]$ in Fig. 9a. As the PC-SAFT parameters for $\mathrm{CH}_{4}$ are already known [18] (Table 4), the ion parameters determined in this work (Table 5) can directly be used to predict the $\mathrm{CH}_{4}$ solubility in ILs. In accordance with the modeling of $\mathrm{CO}_{2}$ solubilities, the effect of $\mathrm{CH}_{4}$ on the dielectric constant of an IL solution was neglected.
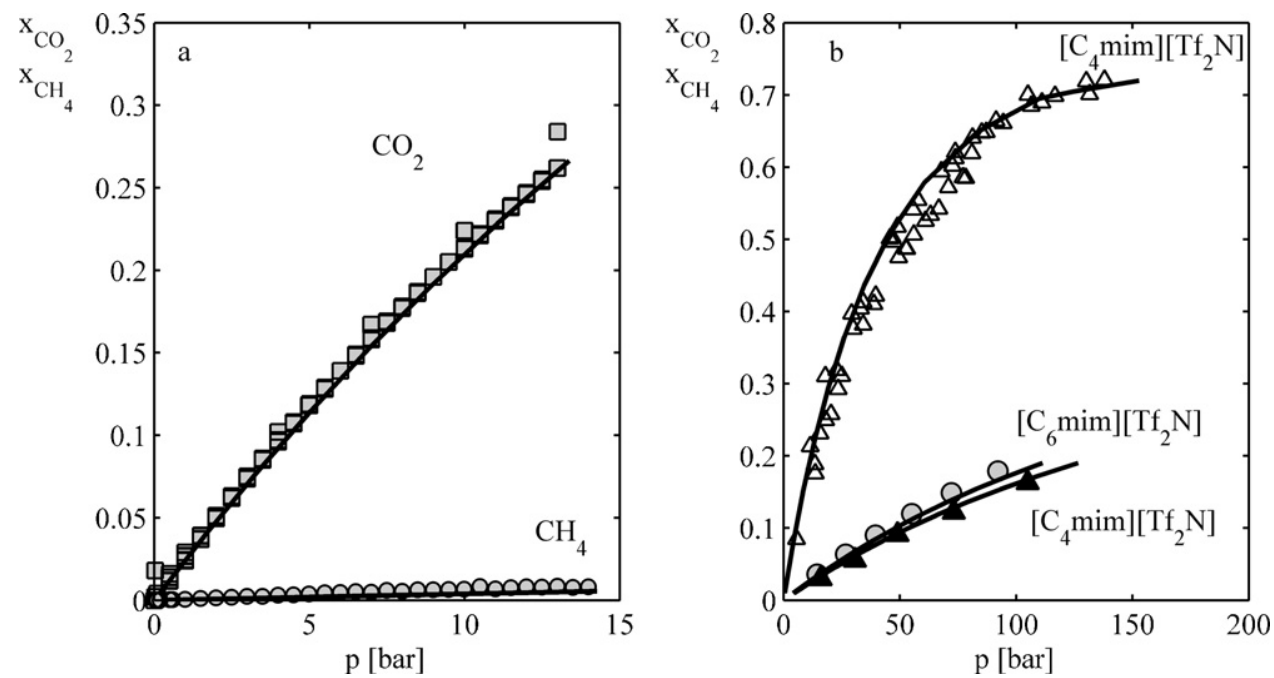

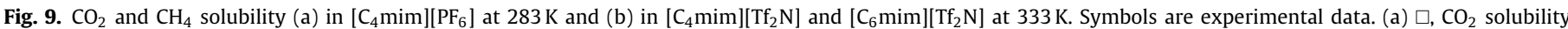

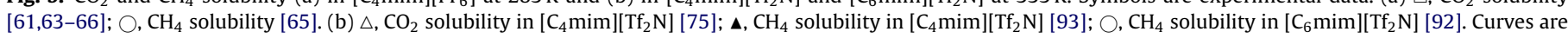
modeling results with parameters listed in Tables 4, 5 and 7. 
Without any adjustable parameter $\left(k_{i j}=0\right)$, the model captures the pronounced difference of $\mathrm{CO}_{2}$ and $\mathrm{CH}_{4}$ solubility in ILs. Applying ePC-SAFT to the $\mathrm{CH}_{4} /\left[\mathrm{C}_{4} \mathrm{mim}\right]\left[\mathrm{PF}_{6}\right]$ system, the gas solubility can be predicted quantitatively as shown in Fig. 9a. Replacing the $\left[\mathrm{PF}_{6}\right]^{-}$ anion by $\left[\mathrm{Tf}_{2} \mathrm{~N}\right]^{-}$, the solubility of both $\mathrm{CO}_{2}$ and $\mathrm{CH}_{4}$ increases tremendously. The $\mathrm{CH}_{4}$ solubility is remarkable but still much lower than that of $\mathrm{CO}_{2}$. Applying the model allows for predicting the $\mathrm{CH}_{4}$ solubility in $\left[\mathrm{C}_{4} \mathrm{mim}\right]\left[\mathrm{Tf}_{2} \mathrm{~N}\right]$ and $\left[\mathrm{C}_{6} \mathrm{mim}\right]\left[\mathrm{Tf}_{2} \mathrm{~N}\right]$ qualitatively. To obtain quantitative results, a $k_{i j}$ had to be assigned between $\mathrm{CH}_{4}$

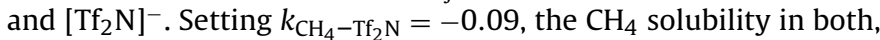
$\left[\mathrm{C}_{4} \mathrm{mim}\right]\left[\mathrm{Tf}_{2} \mathrm{~N}\right]$ and $\left[\mathrm{C}_{6} \mathrm{mim}\right]\left[\mathrm{Tf}_{2} \mathrm{~N}\right]$, could be modeled accurately as shown in Fig. 9b.

After all, using the parameters fitted from the density of pure ILs up to 1000 bar and without any additional adjustable parameters, ePC-SAFT is able to (1) reliably extrapolate/predict the density of pure ILs to higher pressures ( $>1000$ bar), (2) quantitatively predict the $\mathrm{CO}_{2}$ solubility, and (3) quantitatively predict the $\mathrm{CH}_{4}$ solubility in $\left[\mathrm{C}_{4} \mathrm{mim}\right]\left[\mathrm{PF}_{6}\right]$. It can also be used (4) to qualitatively predict the $\mathrm{CH}_{4}$ solubility in both $\left[\mathrm{C}_{4} \mathrm{mim}\right]\left[\mathrm{Tf}_{2} \mathrm{~N}\right]$ and $\left[\mathrm{C}_{6} \mathrm{mim}\right]\left[\mathrm{Tf}_{2} \mathrm{~N}\right]$ and (5) to quantitatively model them with $k_{\mathrm{CH}_{4}-\mathrm{Tf}_{2} \mathrm{~N}}=-0.09$.

\section{Conclusion}

In this work, ePC-SAFT was applied with six strategies to model the density of imidazolium-based ILs and the solubility of $\mathrm{CO}_{2}$ and $\mathrm{CH}_{4}$ in these ILs. It was shown that all strategies can be used to accurately represent the density of pure ILs, but only the ion-based model accounting for Coulomb interactions provides reliable prediction results with respect to the $\mathrm{CO}_{2}$ solubility in ILs.

In the ion-based model accounting for Coulomb interactions, ILs were considered to be completely dissociated into cation and anion. Both ions were modeled as being non-spherical. The Debye-Hückel contribution was used without any additional parameters to describe the Coulomb interactions between charged cation and anion. A set of ion-specific parameters was obtained from fitting to reliable density data measured at pressures up to 1000 bar with a fitting error of $0.14 \%$ on average.

Without any additional adjustable parameters, this model can be used to reliably extrapolate the density of pure ILs at pressures up to 3000 bar from 283 to $473 \mathrm{~K}$. Moreover, the $\mathrm{CO}_{2}$ solubility at temperatures from 293 to $450 \mathrm{~K}$ and pressures up to $950 \mathrm{bar}$ can also be predicted quantitatively based on the comparison to the available experimental data of $11 \mathrm{CO}_{2}$-IL systems. In addition, ePC-SAFT can also be used to represent the $\mathrm{CH}_{4}$ solubility, i.e. the $\mathrm{CH}_{4}$ solubility in $\left[\mathrm{C}_{4} \mathrm{mim}\right]\left[\mathrm{PF}_{6}\right]$ can be predicted quantitatively, and the $\mathrm{CH}_{4}$ solubility in both $\left[\mathrm{C}_{4} \mathrm{mim}\right]\left[\mathrm{Tf}_{2} \mathrm{~N}\right]$ and $\left[\mathrm{C}_{6} \mathrm{mim}\right]\left[\mathrm{Tf}_{2} \mathrm{~N}\right]$ can be predicted qualitatively and represented quantitatively with $k_{\mathrm{CH}_{4}-\mathrm{Tf}_{2} \mathrm{~N}}=-0.09$.

List of symbols

$a$

ARD

$H$

$k_{B}$

$k_{i j}$

$m_{\text {seg,i }}$

M

$N$

NP

$p$

$q$

$T$

$u_{i} / k_{B}$ dimensionless Helmholtz energy

average relative deviation

Henry's constant

Boltzmann constant

binary parameter between two components $i$ and $j$

segment number

molecular weight $(\mathrm{g} / \mathrm{mol})$

association sites per molecule

number of experimental data points

pressure (bar)

charge of ion

temperature $(\mathrm{K})$

van der Waals-interaction (dispersion) energy parameter between two segments $v \quad$ molar volumes

$x \quad$ mole fraction of each component in the liquid phase

$y$ mole fraction of each component in the vapor phase

\section{Greek letters}

$\begin{array}{ll}\chi & \text { abbreviation for an expression } \\ \varepsilon & \text { dielectric constant of a medium } \\ \varepsilon^{\mathrm{AiBi}} / k_{B} & \text { association-energy parameter }(\mathrm{K}) \\ \varphi_{i} & \text { fugacity coefficient } \\ \kappa^{\mathrm{AiBi}} & \text { association-volume parameter } \\ \kappa & \text { inverse Debye screening length } \\ \rho & \text { density }\left(\mathrm{kg} / \mathrm{m}^{3}\right) \\ \sigma_{i} & \text { segment diameter }\end{array}$

\section{Acknowledgments}

X.J. thanks the Swedish Research Council and the Alexander von Humboldt Foundation for financial support. The authors also thank Prof. Maurer at Kaiserslautern University for his valuable comments and discussions.

\section{Appendix A. Supplementary data}

Supplementary data associated with this article can be found, in the online version, at http://dx.doi.org/10.1016/j.fluid.2012.05.029.

\section{References}

[1] http://www.gizmag.com/ionic-liquid-co2-emissions-control/11105/ (15.04.08)

[2] M.J. Muldoon, S. Aki, J.L. Anderson, J.K. Dixon, J.F. Brennecke, J. Phys. Chem. B 111 (2007) 9001-9009.

[3] J. Jacquemin, P. Husson, V. Majer, M.F.C. Gomes, Fluid Phase Equilib. 240 (2006) 87-95.

[4] J.L. Anderson, J.K. Dixon, J.F. Brennecke, Acc. Chem. Res. 40 (2007) 1208

[5] D.G. Hert, J.L. Anderson, S.N.V.K. Aki, J.F. Brennecke, Chem. Commun. (2005) 2603.

[6] M. Solinas, A. Pfaltz, P.G. Cozzi, W. Leitner, J. Am. Chem. Soc. 126 (2004) 16142.

[7] A. Yokozeki, M.B. Shiflett, Appl. Energy 84 (2007) 351.

[8] Y.S. Kim, J.H. Jang, B.D. Lim, J.W. Kang, C.S. Lee, Fluid Phase Equilib. 256 (2007) 70-74.

[9] M. Petermann, T. Weissert, S. Kareth, H.W. Lösch, F. Dreisbach, J. Supercrit. Fluids 45 (2008) 156.

[10] L.F. Vega, O. Vilaseca, F. Llovell, J.S. Andreu, Fluid Phase Equilib. 294 (2010) 15-30.

[11] E.K. Karakatsani, L.G. Economou, M.C. Kroon, C.J. Peters, G.J. Witkamp, J. Phys. Chem. C 111 (2007) 15487-15492.

[12] M.C. Kroon, E.K. Karakatsani, I.G. Economou, G.J. Witkamp, C.J. Peters, J. Phys. Chem. B 110 (2006) 9262-9269.

[13] J.S. Andreu, L.F. Vega, J. Phys. Chem. C 111 (2007) 16028-16034.

[14] J.S. Andreu, L.F. Vega, J. Phys. Chem. B 112 (2008) 15398-15406.

[15] X.Y. Ji, H. Adidharma, Chem. Eng. Sci. 64 (2009) 1985-1992.

[16] X.Y. Ji, H. Adidharma, Fluid Phase Equilib. 293 (2010) 141-150.

[17] X.Y. Ji, H. Adidharma, Fluid Phase Equilib. 315 (2012) 53-63.

[18] J. Gross, G. Sadowski, Ind. Eng. Chem. Res. 40 (2001) 1244-1260.

[19] J. Gross, G. Sadowski, Ind. Eng. Chem. Res. 41 (2002) 5510-5515.

[20] J. Gross, G. Sadowski, Ind. Eng. Chem. Res. 41 (2002) 1084-1093.

[21] J. Gross, O. Spuhl, F. Tumakaka, G. Sadowski, Ind. Eng. Chem. Res. 42 (2003) 1266-1274.

[22] F. Tumakaka, G. Sadowski, Fluid Phase Equilib. 217 (2004) 233-239.

[23] J.B.G. Daldrup, C. Held, G. Sadowski, G. Schembecker, Ind. Eng. Chem. Res. 50 (2011) 3503-3509.

[24] C. Held, L.F. Cameretti, G. Sadowski, Ind. Eng. Chem. Res. 50 (2011) 131-141.

[25] J.B. Grossedaldrup, C. Held, F. Ruether, G. Schembecker, G. Sadowski, Ind. Eng. Chem. Res. 49 (2011) 1395-1401.

[26] C. Held, T. Neuhaus, G. Sadowski, Biophys. Chem. 152 (2010) 28-39.

[27] J. Gross, J. Vrabec, AIChE J. 52 (2006) 1194-1204.

[28] M. Kleiner, J. Gross, AIChE J. 52 (2006) 1951-1961.

[29] J. Vrabec, J. Gross, J. Phys. Chem. B 112 (2008) 51-60.

[30] C. Held, L.F. Cameretti, G. Sadowski, Fluid Phase Equilib. 270 (2008) 87-96.

[31] C. Held, G. Sadowski, Fluid Phase Equilib. 279 (2009) 141-148.

[32] C. Held, A. Prinz, V. Wallmeyer, G. Sadowski, Chem. Eng. Sci. 68 (2012) 328-339.

[33] L.F. Cameretti, G. Sadowski, J.M. Mollerup, Ind. Eng. Chem. Res. 44 (2005) 3355-3362.

[34] Y.A. Sanmamed, D. Gonzalez-Salgado, J. Troncoso, L. Romani, A. Baylaucq, C. Boned, J. Chem. Thermodyn. 42 (2010) 553-563.

[35] R. Taguchi, H. Machida, Y. Sato, R.L. Smith, J. Chem. Eng. Data 54 (2009) 22-27. 
[36] J. Jacquemin, P. Husson, V. Mayer, I. Cibulka, J. Chem. Eng. Data 52 (2007) 2204-2211.

[37] L.P.N. Rebelo, V. Najdanovic-Visak, Z.P. Visak, M.N. Da Ponte, J. Szydlowski, C.A. Cerdeirina, J. Troncoso, L. Romani, J. Esperanca, H.J.R. Guedes, H.C. De Sousa, Green Chem. 6 (2004) 369-381.

[38] R.G. De Azevedo, J. Esperanca, V. Najdanovic-Visak, Z.P. Visak, H.J.R. Guedes, M.N. Da Ponte, L.P.N. Rebelo, J. Chem. Eng. Data 50 (2005) 997-1008.

[39] D. Tomida, A. Kumagai, K. Qiao, C. Yokoyama, Int. J. Thermophys. 27 (2006) 39-47.

[40] R.L. Gardas, M.G. Freire, P.J. Carvalho, I.M. Marrucho, I.M.A. Fonseca, A.G.M. Ferreira, J.A.P. Coutinho, J. Chem. Eng. Data 52 (2007) 80-88.

[41] E. Rilo, A.G.M. Ferreira, I.M.A. Fonseca, O. Cabeza, Fluid Phase Equilib. 296 (2010) 53-59.

[42] J. Klomfar, M. Souckova, J. Patek, J. Chem. Eng. Data 56 (2011) 426-436.

[43] J. Safarov, E. Hassel, J. Mol. Liq. 153 (2010) 153-158.

[44] K.R. Harris, M. Kanakubo, L.A. Woolf, J. Chem. Eng. Data 51 (2006) 1161-1167.

[45] D. Tomida, S. Kenmochi, T. Tsukada, K. Qiao, C. Yokoyama, Int. J. Thermophys. 28 (2007) 1147-1160.

[46] A. Tekin, J. Safarov, A. Shahverdlyev, E. Hassel, J. Mol. Liq. 136 (2007) 177-182.

[47] D. Tomida, A. Kumagai, S. Kenmochi, K. Qiao, C. Yokoyama, J. Chem. Eng. Data 52 (2007) 577-579.

[48] R.L. Gardas, M.G. Freire, P.J. Carvalho, I.M. Marrucho, I.M.A. Fonseca, A.G.M. Ferreira, J.A.P. Coutinho, J. Chem. Eng. Data 52 (2007) 1881-1888.

[49] J. Safarov, W.A. El-Awady, A. Shahverdiyev, E. Hassel, J. Chem. Eng. Data 56 (2011) 106-112.

[50] R.G. De Azevedo, J. Esperanca, J. Szydlowski, Z.P. Visak, P.F. Pires, H.J.R. Guedes, L.P.N. Rebelo, J. Chem. Thermodyn. 37 (2005) 888-899.

[51] C.A.N. De Castro, E. Langa, A.L. Morais, M.L.M. Lopes, M.J.V. Lourenco, F.J.V. Santos, M. Santos, J.N.C. Lopes, H.I.M. Veiga, M. Macatrao, J. Esperanca, C.S. Marques, L.P.N. Rebelo, C.A.M. Afonso, Fluid Phase Equilib. 294 (2010) 157-179.

[52] M.E. Kandil, K.N. Marsh, A.R.H. Goodwin, J. Chem. Eng. Data 52 (2007) 2382-2387.

[53] J. Esperanca, H.J.R. Guedes, J.N.C. Lopes, L.P.N. Rebelo, J. Chem. Eng. Data 53 (2008) 867-870.

[54] E.K. Shin, B.C. Lee, J.S. Lim, J. Supercrit. Fluids 45 (2008) 282-292.

[55] K.R. Harris, M. Kanakubo, L.A. Woolf, J. Chem. Eng. Data 52 (2007) 2425-2430.

[56] K.R. Harris, M. Kanakubo, L.A. Woolf, J. Chem. Eng. Data 53 (2008) 1230.

[57] H. Machida, Y. Sato, R.L. Smith, Fluid Phase Equilib. 264 (2008) 147-155.

[58] Z.Y. Gu, J.F. Brennecke, J. Chem. Eng. Data 47 (2002) 339-345.

[59] K.R. Harris, L.A. Woolf, M. Kanakubo, J. Chem. Eng. Data 50 (2005) 1777-1782.

[60] K.R. Harris, M. Kanakubo, L.A. Woolf, J. Chem. Eng. Data 52 (2007) 1080-1085

[61] Y.S. Kim, W.Y. Choi, J.H. Jang, K.P. Yoo, C.S. Lee, Fluid Phase Equilib. 228 (2005) 439-445.

[62] C. Cadena, J.L. Anthony, J.K. Shah, T.I. Morrow, J.F. Brennecke, E.J. Maginn, J. Am. Chem. Soc. 126 (2004) 5300-5308.
[63] J.L. Anthony, J.L. Anderson, E.J. Maginn, J.F. Brennecke, J. Phys. Chem. B 109 (2005) 6366-6374.

[64] M.B. Shiflett, A. Yokozeki, Ind. Eng. Chem. Res. 44 (2005) 4453-4464.

[65] J.L. Anthony, E.J. Maginn, J.F. Brennecke, J. Phys. Chem. B 106 (2002) 7315-7320.

[66] M.B. Shiflett, A. Yokozeki, AIChE J. 52 (2006) 1205-1219.

[67] M.B. Shiflett, A. Yokozeki, J. Phys. Chem. B 111 (2007) 2070-2074.

[68] D. Camper, C. Becker, C. Koval, R. Noble, Ind. Eng. Chem. Res. 44 (2005) 1928-1933.

[69] P. Scovazzo, D. Camper, J. Kieft, J. Poshusta, C. Koval, R. Noble, Ind. Eng. Chem. Res. 43 (2004) 6855-6860.

[70] P.J. Carvalho, V.H. Alvarez, J.J.B. Machado, J. Pauly, J.L. Daridon, I.M. Marrucho, M. Aznar, J.A.P. Coutinho, J. Supercrit. Fluids 48 (2009) 99-107.

[71] A.M. Schilderman, S. Raeissi, C.J. Peters, Fluid Phase Equilib. 260 (2007) 19-22.

[72] Z.G. Lei, J.A. Yuan, J.Q. Zhu, J. Chem. Eng. Data 55 (2010) 4190-4194.

[73] M.C. Kroon, A. Shariati, M. Costantini, J. Van Spronsen, G.J. Witkamp, R.A. Sheldon, C.J. Peters, J. Chem. Eng. Data 50 (2005) 173-176.

[74] A.L. Revelli, F. Mutelet, J.N. Jaubert, J. Phys. Chem. B 114 (2010) 12908-12913.

[75] S. Aki, B.R. Mellein, E.M. Saurer, J.F. Brennecke, J. Phys. Chem. B 108 (2004) 20355-20365.

[76] S. Hwang, Y. Park, K. Park, J. Chem. Thermodyn. 43 (2011) 339-343.

[77] M. Costantini, V.A. Toussaint, A. Shariati, C.J. Peters, I. Kikic, J. Chem. Eng. Data 50 (2005) 52-55.

[78] K.I. Gutkowski, A. Shariati, C.J. Peters, J. Supercrit. Fluids 39 (2006) 187-191.

[79] A. Shariati, C.J. Peters, J. Supercrit. Fluids 29 (2004) 43-48.

[80] Z.M. Liu, W.Z. Wu, B.X. Han, Z.X. Dong, G.Y. Zhao, J.Q. Wang, T. Jiang, G.Y. Yang, Chem. Eur. J. 9 (2003) 3897-3903.

[81] S.J. Zhang, X.L. Yuan, Y.H. Chen, X.P. Zhang, J. Chem. Eng. Data 50 (2005) $1582-1585$.

[82] A.P.S. Kamps, D. Tuma, J.Z. Xia, G. Maurer, J. Chem. Eng. Data 48 (2003) 746-749.

[83] J. Kumelan, A.P.S. Kamps, D. Tuma, G. Maurer, J. Chem. Eng. Data 51 (2006) 1802-1807.

[84] A. Shariati, K. Gutkowski, C.J. Peters, AIChE J. 51 (2005) 1532-1540.

[85] A. Shariati, C.J. Peters, J. Supercrit. Fluids 30 (2004) 139-144.

[86] B.C. Lee, S.L. Outcalt, J. Chem. Eng. Data 51 (2006) 892-897.

[87] D.J. Oh, B.C. Lee, Korean J. Chem. Eng. 23 (2006) 800-805.

[88] S. Raeissi, C.J. Peters, J. Chem. Eng. Data 54 (2009) 382-386.

[89] P.J. Carvalho, V.H. Alvarez, I.M. Marrucho, M. Aznar, J.A.P. Coutinho, J. Supercrit. Fluids 50 (2009) 105-111.

[90] W. Ren, B. Sensenich, A.M. Scurto, J. Chem. Thermodyn. 42 (2010) 305-311.

[91] J. Kumelan, I.P.S. Kamps, D. Tuma, G. Maurer, J. Chem. Thermodyn. 38 (2006) 1396-1401.

[92] J. Kumelan, A.P.S. Kamps, D. Tuma, G. Maurer, Ind. Eng. Chem. Res. 46 (2007) 8236-8240.

[93] S. Raeissi, C.J. Peters, Fluid Phase Equilib. 294 (2010) 67-71. 